\title{
Context, curriculum and competence
}

\section{Geoff Norman}

Published online: 16 October 2014

(C) Springer Science+Business Media Dordrecht 2014

As I sat down to write this editorial, I found myself staring intently at the corner of my office ceiling. Actually, I wasn't looking at the office ceiling at all-I was staring intently at the inside of my mind, and focusing (actually not focusing) on the office ceiling so I would not be distracted by the contextual cues in my environment.

I was reflecting on a recent event. A few days ago, I was in Hamburg at the meeting of the German Medical Education Association, where I had the honour of being invited as a keynote speaker. During my talk, I showed a graph comparing high fidelity to low fidelity simulations, showing a minimal and not significant advantage for the high fidelity (Norman et al. 2012). One of the domains I looked at was auscultation, where all the studies compared Harvey to a much lower fidelity simulation, typically a CD recording.

After the talk, I was approached by a colleague who counseled me that comparisons using Harvey were not really appropriate as there were much higher fidelity simulations available now. He apparently did not accept the notion that, if Harvey showed no empirical advantage over something as simple as a $\mathrm{CD}$, it was unlikely that a more sophisticated simulation would show an effect. Of course he may be right. Perhaps with a simulation that blinked, cried out, or panted, the context may be sufficiently more realistic that it would enhance learning. Or perhaps not.

Indeed, an implicit assumption of many high fidelity simulations is that the more the plastic patient resembles a real patient, the better the transfer to the "real" world. That is, it is assumed that learning to listen to a heart in an almost-real plastic chest will make it easier for students to recognize an abnormal heart sound in an actual patient situation. A bit like presuming that watching and listening to a Beethoven symphony on YouTube will enable you to recognize it better than just hearing it on an iPod. Perhaps. But perhaps not.

However, this editorial is not about simulation, for a very good reason. Simulation is only one of very many places in health sciences education where we presume that the

G. Norman $(\bowtie)$

McMaster University, Hamilton, ON, Canada

e-mail: norman@mcmaster.ca 
closer the learning situation resembles the real clinical situation, the easier students will be able to transfer their learned skills to practice. Let me briefly describe some other ways in which this assertion arises in education. I acknowledge and thank Mahan Kulasegaram and Tahrin Mahmood for these definitions, which I have taken the liberty of reproducing below. They are not intended to be necessary and sufficient, but simply to illustrate the landscape of educational strategies and theories that posit advantages for learning in "authentic" settings:

\section{Cognitive Apprenticeship}

Cognitive apprenticeship (Collins et al. 1989) "imbeds the learning of skills and knowledge in the social and functional context of their use."

\section{Situated Cognition}

Situated cognition, also known as situated learning, focuses on goal-based scenarios to ensure that the skill is learned in its context. It is believed that the learning takes place when the student is engaged in a complex, real-life situation (Young 1993, Herrington and Oliver 1999).

\section{Workplace Learning}

Workplace learning takes workplace as a community of practice. At a workplace an employee is learning at an individual and collective level. Participation is considered vital in this model.

\section{Authentic Assessment}

Authentic assessment is the form of evaluation that asks students to perform realworld tasks and demonstrate meaningful application (Woolley and Jarvis 2007).

\section{Problem-Based Learning}

One of the purported advantages of PBL is that the basic science is learned in the context of a clinical problem, so ostensibly could be recalled easier in the clinical context.

The common denominator of all these approaches is that they presume that the more authentic the learning situation, the better the learning and transfer. It matters not whether we are talking about the environment-learning should occur in the workplace setting, the stimulus - the stimulus should be realistic, or the problem-concept learning should be imbedded in a clinical problem.

The strange thing is that despite the pervasiveness of this view, there appears to be precious little evidence to support the basic claim that learning in an authentic context will enhance transfer. Indeed, it seems that a single paper is cited almost universally to support this claim-Godden and Baddeley (1975). According to Google it is a citation classic, with 1,092 citations.

It is worth reviewing this study, if only to point out that it is a poor basis for justifying the role of authentic context. Divers of the Cambridge University Diving Club, memorized lists of 36 unrelated words on land, and underwater. Words learned on land were recalled better on land; those learned underwater were recalled better underwater. The problem, as pointed out by Smith and Vela (2001), is that under these circumstances, there were really no other cues or associations they could use to help memory, so the environment had a relatively strong effect. However, if there were conceptual associations between the words, as would likely be the case in any real-world educational situation, these contextual effects will diminish. Perhaps that is the reason why Koens et al. (2003) were unable to replicate this effect in a medical environment. 
More generally, as we peruse the range of activities subsumed under these various approaches to learning, it is evident that there are multiple ways the term "context" is being used. When PBLers talk about context, they typically mean the paper clinical problem in which the basic science is learned. Conversely, advocates of situated cognition are talking about the physical setting-workplace or seminar room. These represent very different views about the potential role of context. Koens et al. (2005) has advanced a conceptual framework that proposes three kinds of context: physical-the environment in which learning or application takes place, semantic - the relevant context of the task (such as a PBL problem) and commitment-the motivation or sense of responsibility that is engendered by the learning material. They do not present any data about the relevant contribution of each, but then in all likelihood such data do not exist.

This framework is quite analogous to some current thinking about the role of fidelity in simulation (Grierson 2014) in which one can separate out the critical elements of the simulation (semantic) from the overall appearance and realism (physical) and the extent to which the simulation creates emotional involvement (commitment).

More fundamentally, this highlights just how complex the issue of the role of context in learning becomes. To match semantic context in a PBL tutorial is relatively simple, and indeed is the central element of PBL instruction. To match physical context to achieve cognitive apprenticeship or situated cognition requires totally different kinds of manipulation, such as arranging for every student to be based in a hospital somewhere. As far as the commitment dimension, I cannot see any way to build this in as a curriculum dimension without creating some kind of Hollywood action movie.

For that matter, what does it mean to match context? We assume that teaching in a hospital ward is sufficient to achieve transfer to a hospital setting. But this seems quite cavalier. Are all hospital wards the same? Do the specific features of the room like colour of the walls matter? Where you are in the room? Who is with you? When I think about some conversation I had with someone, I often deliberately try to recall the context, knowing that will help me reconstruct the conversation. But when I do, it's not just any restaurant or pub (many good ideas occur in pubs) —it's the grad student pub on campus where we were sitting outside and Scott was on my left and John on my right and it was a warm sunny day.

We're not done yet. Is context a good thing or a bad thing? Bransford et al. (1999) has argued that strategies such as PBL can have deleterious effects, as learning a concept in a problem context may limit transfer. We tend to remember the concrete details, not the abstract concepts, which is why far transfer (changing the semantic context) is difficult. If you've learned about Laplace Law in the context of a patient in heart failure, you may have difficulty seeing that an aortic aneurism is the same underlying process. Kulasegaram and Min (2012) has shown that the semantic context can be both friend and enemy. Strategies such as mixed practice are deliberately designed to present problems across multiple contexts, and therefore reduce the possible negative impact of semantic context.

Physical context has similar problems. While it may seem desirable for students to learn in a work setting, the workplace is a very complex environment designed to optimize delivery of health care, not learning. The multiple constraints may lead to issues such as increased extraneous load, which can harm learning (Koens et al. 2005).

Similar issues arise in the commitment dimension, where the level of emotional commitment may lead to increased anxiety and reduced learning. As Koens et al. (2005), point out, there is an optimal level of anxiety for learning, as expressed in the Yerkes-Dodson Law (1906; in Cohen 2011), now over 100 years old. 
In my view, the case for the role of authentic contexts, however defined, remains unproven. Our students are not automata, and can make deliberate choices to adapt their thinking to focus on relevant dimensions and screen out distractions occurring in the physical environment (every distraction, that is, but their smart phone's insistent buzz). That was what I was doing when I stared at the ceiling, and is a central point of the Smith and Vela (2001) article cited earlier.

We do not need to prove that students can learn useful and applicable knowledge in physical contexts removed from the application setting. Millennia of students have learned in this way. Somehow we have managed to produce graduate engineers who can build bridges and physicians who can diagnose rare diseases, even though they may only have read about them in classrooms. But if you need evidence, a series of recent studies by Durning et al. $(2010,2012)$ has shown repeatedly that students learn to transfer knowledge to diagnose new problems just as effectively when the knowledge is presented as a written case as when it is shown as a video or standardized patient.

\section{References}

Bransford, J. D., Brown, A. L., \& Cocking, R. R. (1999). How people learn: Brain, mind, experience, and school. Washington: National Academy Press.

Cohen, R. A. (2011). Yerkes-Dodson Law. In J. S. Kreutzer, J. DeLuca \& B. Caplan (Eds.), Encyclopedia of clinical neuropsychology (pp. 2737-2738). New York: Springer.

Collins, A., Brown, J. S., \& Newman, S. E. (1989). Cognitive apprenticeship: Teaching the crafts of reading, writing, and mathematics. In L. B. Resnick (Ed.), Knowing, learning, and instruction: Essays in honor of Robert Glaser (pp. 453-494). Hillsdale, NJ: Lawrence Erlbaum Associates.

Durning, S., Artino, A. J., \& Pangaro, L. (2010). Redefining context in the clinical encounter: Implications for research and training in medical education. Academic Medicine, 85, 894-901.

Durning, S., LaRochelle, J., Pangaro, L., Artino, A., Boulet, J., van der Vleuten, C., et al. (2012). Does the authenticity of preclinical teaching format affect subsequent clinical clerekshipm ooutcime? A prospective randominzed trial. Teaching and Learning in Medicine, 24, 177-182.

Godden, D. R., \& Baddeley, A. D. (1975). Context-dependent memory in two natural environments: On land and underwater. British Journal of Psychology, 66, 325-331.

Grierson, L. E. (2014). Information processing, specificity of practice, and the transfer of learning: considerations for reconsidering fidelity. Advances in Health Science Education: Theory and Practice., 19, 281-289.

Herrington, J., \& Oliver, R. (1999). Using situated learning and multimedia to investigate higher-order thinking. Journal of Educational Multimedia and Hypermedia, 8(4), 401-422.

Koens, F., Mann, K. V., Custers, E. J., \& Ten Cate, O. T. (2005). Analysing the concept of context in medical education. Medical Education, 39, 1243-1249.

Koens, F., Ten Cate, O. T., \& Custers, E. J. (2003). Context-dependent memory in a meaningful environment for medical education: in the classroom and at the bedside. Advances in Health Science Education: Theory and Practice, 8, 155-165.

Kulasegaram, K., Min, C., Ames, K., Howey, B., Neville, A., \& Norman, G. R. (2012). The effect of conceptual and contextual familiarity on transfer performance. Advances in Health Sciences Education, 17(4), 489-499.

Norman, G., Dore, K., \& Grierson, L. (2012). The minimal relationship between simulation fidelity and transfer of learning. Medical Education, 46, 636-647.

Smith, S. M., \& Vela, E. (2001). Environmental context-dependent memory: A review and meta-analysis. Psychonomic Bulletin \& Review, 8, 203-220.

Woolley, N., \& Jarvis, Y. (2007). Situated cognition and cognitive apprenticeship: A model for teaching and learning clinical skills in a technologically rich and authentic learning environment. Nurse Education Today, 27, 73-79.

Young, M. F. (1993). Instructional design for situated learning. Educational Technologty Research and Development, 41, 43-58. 